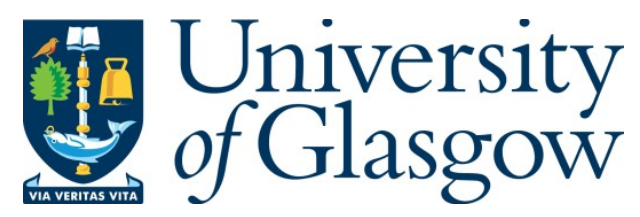

Solomon, T. (2019) Rhythm and mobilization in international relations. International Studies Quarterly, 63(4), pp. 1001-1013.

(doi: 10.1093/isq/sqz074)

This is the Author Accepted Manuscript.

There may be differences between this version and the published version. You are advised to consult the publisher's version if you wish to cite from it.

https://eprints.gla.ac.uk/191924/

Deposited on: 7 August 2019

Enlighten - Research publications by members of the University of Glasgow http://eprints.gla.ac.uk 


\title{
Rhythm and Mobilization in International Relations
}

Ty Solomon

University of Glasgow

ty.solomon@glasgow.ac.uk

Accepted for publication at International Studies Quarterly (August 2019)

\begin{abstract}
:
International Relations (IR) has rarely considered rhythm as a topic of analytical attention. Yet rhythms permeate many social and political phenomena, and their study contributes to core debates and empirical insights in contemporary IR. Rhythms are similar to but distinct from other forms of repetitive, iterative social action that have garnered increasing interest in IR, such as practices, habits, and routines. Each of these phenomena has rhythmic elements, but not all rhythmic phenomena are practical, habitual, or routine. Rhythm, then, is a distinct category of iterative action that is effectively positioned to unpack a wider array of practices in a broader range of cases. Moreover, contrary to common conceptions as simple repetition, the multiplicity and dynamism of social rhythms hold the potential to produce novel political formations. This article outlines a framework for the study of rhythms in international relations by delineating some key features of social rhythms and three kinds of socio-political effects that they have in collective contexts. These theoretical developments are empirically applied to understand neglected aspects of mass mobilization during the Arab uprisings of 2011.
\end{abstract}


One of the most overlooked aspects of first-hand accounts of the Arab Spring,

Occupy Wall Street, and other transnational mass events of recent years is how notions of rhythm appear central to the experience of the events. ${ }^{1}$ Many people expressed the power of rhythms similar to this report from a protestor in Tahrir Square in Cairo, who vividly recounts how:

We started chanting what Tunisians before us had demanded: 'The people demand the fall of the regime.' We had moved from simple, achieveable demands to demanding the fall of the regime! I felt that the matter was becoming more serious and critical. I was confused. I had conflicting feelings of joy and pride but also puzzlement and shock. 'So what?' I said to myself. 'Do we have anything to lose? And spontaneously I started repeating the words with them as loud as I could, with all my emotion: "The people want the fall of the regime"' (Prince 2015, 63).

Many other accounts from the 2011 uprisings and other such events of recent years highlight similar rhythmic aspects of political experience: marching together, mass chanting and singing, pulsating crowds, auditory and visual reverberations throughout public spaces, and the give-and-take nature of street battles with police and security forces. While expressions of power and political awakening are common at such times, they are of interest here for their rich implications for thinking through some key debates surrounding emotions, bodies, and power in contemporary International Relations (IR).

Specifically, such accounts challenge some of the prevailing assumptions in IR regarding repetitive, iterative social action. IR has in recent years seen dramatically increased interest in such action, mainly through work on practices (Adler and Pouliot 2011;

\footnotetext{
${ }^{1}$ Author's note: I greatly appreciate the constructive and engaging feedback on various drafts of this paper from many friends and colleagues, including Sophia Dingli, Faye Donnelly, Naomi Head, Simon Koschut, Rhys Machold, Jennifer Mitzen, Daniel Möller Ölgaard, Ido Oren, Keith Smith, Eric Ringmar, and Eric Van Rythoven. Particular thanks to Cian O'Driscoll, Andy Hom, and Chris McIntosh for comments on several drafts and for enjoyable brainstorming about rhythm during this paper's long gestation. Thanks as well to audiences at the 2016 and 2018 International Studies Association conferences, to Brent Steele, Alex Homolar, and other participants at the 2017 ISA workshop on "Fear, Trauma, and Belonging: the Everyday of Ontological Security," the 2016 "Time and the Politics of (In)Security" workshop held at the University of Glasgow and supported by the Glasgow Global Security Network, the 2017 Millennium conference, the University of Edinburgh International Relations Research Group, and the Centre for International Peace and Security Studies at McGill University. Finally, I'm indebted to three anonymous reviewers whose challenging and encouraging feedback greatly improved the paper.
} 
Bueger and Gadiner 2015; McCourt 2016; Neumann 2002), habits (Hayes 2015; Hopf 2010; Howard 2015), and routines (Mitzen 2006; Mitzen and Schweller 2011; Steele 2008;

Kinnvall 2004; Zarakol 2010). Rhythms, however, have rarely been examined by IR scholars. Yet rhythms permeate many natural and social phenomena, and are analysed across a wide range of fields. Although different from rhythm, notions of repetition play a role in many mainstream and critical IR theories. In realism, anarchy and systemic pressures on states result in continual balances of power, and the "striking sameness in the quality of international life through the millennia" (Waltz 1979, 66). In neoliberal institutionalism and other rationalist theories, iterative interactions provide incentives for cooperation (Keohane 1984, 75). In constructivist frameworks habits play a key role in how deeply states internalize norms of different cultures of anarchy (Wendt 1999, 310-11). In feminist and poststructuralist work, the performativity of gender roles, identities, and subjectivities renders them ongoing repetitive processes rather than fixed entities (Epstein 2013; Wilcox 2015).

Yet only in recent years has the politics of repetitive social action been scrutinized more substantively in work on practices, habits, and routines. While closely related, rhythms offer novel perspectives on similar processes yet also open up new issues of concern which remain largely ignored in IR. Although contributing rich insights into contemporary global politics, current frameworks encounter significant analytical problems when faced with the highly visible roles of repeated, iterative - yet rhythmic - social action outside of the contexts typically studied in this work. As detailed below, IR research on iterative action suffers from at least two key oversights. First, how do we account for the effects of repetitive social action during unsettled times? Much of this work focuses on actors within highly "settled" institutionalized settings (as in practice and habit research) or on the re-establishment of social order (as in routines research). Second, how do we account for the power of iterative action in collective contexts, rather than highly-positioned individuals or small groups (such 
as diplomats and other elites)? Elite individuals and small groups certainly engage in power politics in such contexts (Adler-Nissen and Pouliot 2014). Yet when examining mass collective situations, the kind of power generated from iterative action, and its constituent elements, qualitatively shifts. Rhythmic action, as argued below, links individuals and collectives, and intensifies collective emotions, generates emergent identities and subjectivities, and (re)constructs social meanings of public spaces that often anchor mass politics outside of highly institutionalized settings.

While there is no single definition of rhythm across the interdisciplinary literature, social and historical conceptualizations tend to exceed common associations with metronomic, fixed patterns to instead focus on the more lived, dynamic, and generative aspects of rhythms. One certainly sees aspects of rhythms in IR work on practices, habits, and routines. Yet, rhythms are also observed in contexts where normal practices, habits, and routines have been disrupted. Rhythm, in this sense, is a distinct category of iterative action that has been largely ignored in IR yet helps to explain its power in cases that fall outside of existing IR work. Despite their ubiquity in social life and nearly all prominent transnational social movements of recent years, rhythms have rarely been examined in and of themselves as aspects of collective mobilization and power that entail emotional, embodied, and everyday elements.

As a key yet underexamined factor in the politics of mass mobilization, rhythms contribute to what Hannah Arendt called "collective power," "the human ability not just to act but to act in concert" (Arendt 1970, 44). In IR, growing interest in power and mobilization (Goddard and Nexon 2016; Krebs 2018; Van Rythoven 2017; Simmons 2016; Tilly 2008), along with related work on the power of collective emotions (Hall and Ross 2015; Hutchison and Bleiker 2014; Fierke 2013), and micropolitical approaches (Kertzer 2016; Pearlman 2013; Solomon and Steele 2017), point to efforts at re-casting "power 
politics" away from state-based or "top-down" frameworks most often emphasized in IR. While debates about power often take such critiques as their point of departure (Barnett and Duvall 2005; Berenskoetter 2007), there are many aspects of power that remain untapped in IR's current conceptualizations, which rhythmic effects often exceed. The visceral, embodied, and collective aspects of rhythms help to produce the emotional intensities that concatenate and sustain mass mobilizations (Goddard and Nexon 2016, 5; Tilly 2008, 14). In this sense, rhythms offer new insights on collective efforts at power politics.

The argument is developed in three sections. The next section outlines the shortcomings of current IR research on repetitive, iterative social action. The second section then distills some key themes from the interdisciplinary literature on rhythms that help to account for their political significance. The third section applies these insights to a fresh reading of the Arab Spring. While much of this literature has rightly focused on the role of political and economic grievances and social media, a focus on rhythms highlights some of the neglected aspects of the mobilizing power of rhythmic action. The conclusion ends with some suggestions for future research.

\section{Repetitive, Iterative Social Action in IR}

IR has seen rapidly increasing interest in the repetitive and iterative aspects of everyday social action in global politics, with much of it concentrated in research on practices, habits, and routines. Much of the work on practices focuses on "concrete situations of life in which actors perform a common practice and thus maintain social orderliness" (Bueger and Gadiner 2015, 3). Or, as Adler and Pouliot (2011, 4-5) argue, practices are "socially meaningful patterns of action" which can both challenge or stabilize social

structures. Research on habits emphasizes the "“automatic system' in the brain" and the "unreflective reactions we have to the world around us" (Hopf 2010, 541, 544). Routines are a key concept in ontological security research, where they help to maintain "security of the 
self," or identity security, alongside traditional concerns about physical security (Kinnvall and Mitzen 2017; Kinnvall 2004; Mitzen 2006; Steele 2008). ${ }^{2}$

Despite their diversity, a key common thread is that each literature foregrounds the significance of iterative aspects of social action. Practices, for example, are variously defined as "patterned, in that [they] generally exhibit certain regularities over time and space" (Adler and Pouliot 2011, 6), or as "repetitive patterns" and that the social order "requires work and emerges from routines and repetitiveness" by agents (Bueger and Gadinger 2015, 456, 453). Habits are often acquired through "repeated exposure to how things are, and are not, done," and are mostly "unintentional, unconscious, involuntary, and effortless" (Hopf 2010, 542, 541). Similarly, routines are typically defined by their repetition, are "internally programmed cognitive and behavioral responses to information or stimuli" (Mitzen 2006, 346), and are often "“reflexively monitored"” on a "regular basis" by agents to establish order and predictability (Steele 2008, 51, 61).

While offering major insights into international order, IR research on repetitive, iterative action nevertheless encounters analytical problems when faced with the diverse kinds of experiences and effects to which they often give rise. Although we see hints of rhythms in practices, habits, and routines (See Adler and Pouliot 2011, 5; Pouliot 2010, 21, 25; Steele 2010, 40), there are many different kinds of iterative action observed in politics that exceed the scope of current research. More importantly, current work ignores the significance of iterative action during unsettled times and in collective contexts.

Although sensitive to their contingency (Bueger and Gadinger 2015, 453), practice research tends to focus on behavior in highly institutionalized contexts such as embassies and state agencies (Adler and Pouliot 2011; Pouliot 2010). However, less clear is how practice theories might make sense of repetitive action seen in contexts of collective mobilization and

\footnotetext{
2 See Oren and Solomon (2015) for similar work on repetition in securitization.
} 
experiences of "ordinary" people during unsettled times of major social change. ${ }^{3}$ Habit frameworks similarly focus on the importance of bodily, patterned actions (Hopf 2010). Yet these theories often emaphasize the static aspects of social action: where "the logic of habit predominates, international relations have less agency, less rationality, and less uncertainty than other logics would lead us to expect" (Hopf 2010, 540). When the issue of endogenous change is addressed, habit theorists rightly note the importance of improvisation and the uniqueness of individuals (Hopf 2017, 7). Yet rhythm points to the importance of interactions with others in expressing everyday repertoires through which improvisations and dynamic change may be generated, as the often intense political effects of rhythm emerge when performed collectively with others.

These questions, then, are where current theories of iterative action fall short. The empirical cases below pose the orthogonal problem of making sense of iterative action outside of highly institutionalized contexts and in non-routine, uncertain collective settings of social upheaval, and with the repetitive action neither clearly rule-based practice (Bueger and Gadinger 2015, 455) nor habitual (Hopf 2010). Mass mobilization in cases such as the Arab Spring are contexts where we still observe vivid repetitive, iterative action, yet are not the practices, habits, and routines on which IR scholars focus. Of course, rhythmic action may also occur in elite or highly institutionalized contexts, and might also be observed during settled times - rhythms can often shade into these other kinds of iterative action. However, as most current IR research focuses on practices, habits, and routines, it has yet to recognize the collective power of iterative action in unsettled contexts specifically - which often herald major political change. ${ }^{4}$

\footnotetext{
3 There is debate over the extent to which practice theories are equipped to explain change (Bueger and Gadinger 2015, 456; Duvall and Chowdhury 2011; Ringmar 2014; Schindler and Wille 2015). However, the critique offered here is less about specific mechanisms of practices than it is about more general scope conditions of theories of iterative action.

${ }^{4}$ On settled and unsettled times, see Krebs (2015) and Swidler (1986).
} 
Rhythm, then, is a distinct category of repetitive action that may overlap with practices, habits, and routines (Bueger and Gadinger 2015, 453; Hopf 2010, 541; Steele 2008, 61), yet is not coterminous with them. Rhythm offers an account of the qualitative shift observed in the power of repetitive action when moving from elites or small groups in more or less formal settings, to the politics collective mobilizations.

Related work explores corollary themes surrounding the politics of music and dance. Music has long been associated with politics (such as national anthems, anti-war songs, and civil rights and anti-apartheid songs), and recent IR research examines these issues within the broader contexts of aesthetics (Bleiker 2009) and popular culture (Caso and Hamilton 2015). Davis and Franklin $(2015,134)$ argue that music offers IR scholars empirical resources as culture and through its sensory aspects, while other work emphasizes its power to motivate political engagement (Pruitt 2013; see also Hast 2018). Others focus more explicitly on the body, such as Åhäll's (2018) use of “dance” as a metaphor to examine the intersections of bodies, affect, and movement in the everyday politics of militarization, and Mills' (2016) work on the transgressive political potential of dance. ${ }^{5}$ This important work not only recognizes the neglected politics of music and dance but in doing so also acknowledges the political signficance of rhythmic phenomena. The argument here builds upon these themes, and more explicitly develops rhythm itself as a primary theoretical resource to understand its role in the collective power of mobilization.

To help unpack the significance of rhythms, the following section distills some key themes from the interdisciplinary literature that illustrates their central role in social and political life, and outlines how these contribute to research on repetitive action in contemporary IR theory more broadly.

\section{Rhythms, novelty, and embodied collectives}

\footnotetext{
5 See related work on the "everyday" in global politics (Enloe 2014; Stanley and Jackson 2016; Sylvester 2013).
} 
Rhythms are explored across a wide range of fields such as history (Zimmer 2013), neuroscience (Buzsáki 2006), geography (Edensor 2010), anthropology (You 1994), sociology (Collins 2004), and philosophy (Dewey 2009; Lefebvre 2004), among others. ${ }^{6}$ Dictionary definitions of rhythm typically refer to fixed interval and metronomic frequencies. $^{7}$ To be sure, many common notions of rhythm emphasize the even frequency and duration of a patterned interval, such as the ticking of a clock, oceanic tides, and the changing of the seasons. However, research on the social and historical aspects of rhythm often focuses on its lived temporal, affective, and spatial elements. ${ }^{8}$ Human rhythms are rarely as perfectly metronomic as a ticking clock, and it is often this "imperfection" through which social rhythms proceed at different speeds and frequencies yet maintain perceptions of tempo. It is also through such variation, as well as multiple social rhythms overlaying and intermingling with one another, that difference and change may come about through rhythmic action. A definition of social rhythms, then, should include these experiential features, such as the anticipations and expectations it fosters, its variations and cascades in affective intensity, and more or less patterned actions within a perceived series (You 1994).

From this interdisciplinary work we can distill some key insights regarding the collective and embodied aspects of rhythms, and their role in bringing about novel political formations through their variability and multiplicity. Specifically, rhythms have at least three kinds of novel political effects: they intensify collective emotions, generate emergent identities and subjectivities, and (re)construct social meanings of public spaces.

\section{Embodied collective rhythms}

Rhythms are core to the functioning of the body. From the heartbeat and sensorimotor rhythms to circadian rhythms (Weil and Nelson 2014) to communication speeds

\footnotetext{
${ }^{6}$ Scholars of nationalism have remarked on the importance of rhythm (Smith 1991, 162), as well as scholars interested in rhythms of electoral systems (Orr 2015).

${ }^{7}$ https://en.oxforddictionaries.com/definition/rhythm

8 See also Steele 2010 on the aesthetic power of rhythm.
} 
between brain regions (Buzsáki 2006), the study of rhythms in physiology and neuroscience is well-established. Rhythms of different layers and speeds are part of normal brain and body functioning, just as abnormal neural synchronization is closely associated with a range of disorders such as schizophrenia and Parkinson's (Uhlhaas and Singer 2006). ${ }^{9}$ Work in social psychology helps to contextualize bodily rhythms at an interactive level. Early in socialization rhythms are key to language acquisition (Langus et al. 2016), and working together in synchrony with others increases the chances of success in achieving a goal (Valdesolo et al. 2010). People acting in synchrony often cooperate more in group efforts, even when this involves personal sacrifice (Wiltermuth and Heath 2009).

Through the development of intersubjective structures, the social and political implications of rhythm begin to emerge. Crowd theory, for example, has long been established in the social sciences (Borch 2012), and rhythms have often been associated with crowd contexts (Canetti 1984). One of the reasons for the renewed interest in crowds is due to states' increasing efforts at monitoring and controlling them, particularly with recent years' social movements, uprisings, and protests (Aradau 2015). While early crowd theories viewed them as irrational (Borch 2012, 34-43), contemporary work aims at a more nuanced conceptualization of such collective behavior (Van Ness and Summers-Effler 2016). In contrast to rationalist and constructivist approaches, Aradau argues that "neither grievances nor social identity are sufficient in themselves to constitute a crowd" (Aradau 2015, 169). The sheer physical presence of bodies in common spaces amplifies crowds' symbolic and affective power, beyond the strategic interests or social identities that may have initially motivated their formation.

Other work clarifies some of the specific mechanisms, processes, and constituent roles of rhythms in social collectives. Durkheim long ago recognized the significance of the

\footnotetext{
${ }^{9}$ Although neglecting the specifically rhythmic functioning of these processes, see Holmes' 2013 incorporation of mirror neurons for the study of diplomacy.
} 
“collective effervescence” produced by ritual gatherings (Durkheim 1965, 242). Collins' (2004) work in particular is useful in unpacking the affective and embodied features of rhythms in collective events, such as mass protests. These "interaction rituals" are sites "in which participants develop a mutual focus of attention and become entrained in each other's bodily micro-rhythms and emotions" (Collins 2004, 47). For these to cohere, at least four factors are typically present: multiple people physically assembled in the same place so as to be affected by each others' bodily movements; boundaries to outsiders such that participants have a sense of who is participating and who is not; a common focus of attention; and a shared common mood or emotional experience (Collins 2004, 48).

When these ingredients come together, they help to enhance group solidarity, emotional energy, produce affective investment in the foci of attention, and can inflate feelings of morality (Collins 2004, 49). At a conversational level, various rhythmic synchronizations facilitate these processes, such as buildup of shared laughter, conversational turn-taking, pitch, tempo, and tone of voice. At larger collective levels such mechanisms are magnified. As Collins explains, "bodily presence makes it easier for human beings to monitor each others' signals and bodily expressions; to get into shared rhythms, caught up in each others' motions and emotions; and to signal and confirm a common focus of attention and thus a state of intersubjectivity" (Collins 2004, 64). These factors help to produce feelings of solidarity both with the group and toward the cause at hand.

These are also the processes through which rhythms contagiously diffuse and scale-up to more macro-levels of concern. As emotions and rhythms typically occur together and mutually amplify each other, rhythms often spread through similar processes as emotions. Following Hall and Ross $(2015,856-7)$, theorizing how affective experience emerges from interactions of individuals avoids the problems usually associated with transposing individual-level theories to collectives. As rhythm is embodied action, it spreads through 
channels of bodily contagion, such as postural, facial, and vocal imitation and feedback (Hatfield et al. 2014). Such interactions often occur on a largely nonconscious register and are processes through which rhythms contagiously disperse and transform (Hatfield et al. 2014). Rhythms can diffuse through conscious and strategic adoption, but also through nonconscious contagion and transmission.

Not everyone in mass events will participate in collective rhythms. Others may engage in rhythms that differ from what may be the dominant crowd rhythms, yet still be seen as a member of the group. As these insights suggest, rhythms range from looser or tighter synchronizations, faster or slower movements, and denser or lighter engagements. Yet rhythmic movements overall are often key to the collective power of the group or the character of an event. The rate of interactions during a ceremony, the pace of speakers, or the presence or absence of music will often define the experience of an event (Knottnerus 2014, 316). Importantly, "increases in the interactional pace influenced by either the rate of interactions or rhythmic motion intensify the collective emotions shared" during the event (Knottnerus 2014, 317). When merged with a shared focus of attention and either physical or online-mediated co-presence (Ross 2014, 29-31), increased emotional intensity fosters more solidified committment to the events and their symbolic themes.

Novelty through rhythms: intensity, generation, and (re)construction

While rhythms are commonly conceived as simply repetitive, their variability in embodied collective expressions can be the source of both social stability and change. The work of philosopher John Dewey and spatial theorist Henri Lefebvre both explores how rhythm often differs from strictly repetitive action, and how rhythms can facilitate the emergence of new social forms. Dewey, for example, conceived rhythm as loose patterning of movement through variations in intensity. "Rhythm," for Dewey $(2009,154)$, "is ordered variation of changes," and when there is a "uniformally even flow, with no variations of 
intensity or speed, there is no rhythm." Dewey uses a natural analogy to explain. A torrential flood or a calm pond are not rhythmic, yet ripples across a pond or the beating wings of a hummingbird are. The difference is that "there must be energies resisting each other" (Dewey 2009, 155; see also Steele 2010, 36). Gains in intensity, compressions of opposing force, and the latter overcoming the former form the basis of rhythms. Neither pure change nor pure stasis, rhythm is marked by shifting intensities, speeds, and tempos. Similarly, Lefebvre suggests that rhythms help to (re)construct the social meanings attached to particular spaces and places. Lefebvre follows Dewey in contending that rhythm is not mere repetition of sameness, but instead entails potential for novelty and change with each iteration. "While mechanical repetition works by reproducing the instant that precedes it, rhythm preserves both the measure that initates the process and the re-commencement of this process with modifications, therefore with its multiplicity and plurality" (Lefebvre 2013, 87). In other words, each beat, movement, and iteration fosters the possibility of an altered beat, shifted movement, and new rhythmic succession.

As a concept, then, rhythm captures a sense of tentative stabilities but also the potential for novelty emerging from iterative action, and highlights movements that constitute tensions between stability and change, actual and potential, and settled and emergent. Through collective expression of these tensions, rhythms can facilitate the emergence of novel political formations. Particularly in contexts of mass mobilizations, collective rhythms can be highly productive in effecting at least three kinds of political work.

First, rhythms tend to intensify collective emotions. Military drill is a classic example. As Barkawi $(2017,173)$ notes, drill fosters "sentiments of affinity" among recruits as being part of a larger collective. Historian William McNeill, recalling his own experience in the US military, details how "words are inadequate to describe the emotion aroused by the prolonged movement in unison that drilling involved" (McNeill 1995, 2). Close bodily 
synchronization, involving "moving big muscles together and chanting, singing, or shouting rhythmically," constitutes a kind of "muscular bonding" and fosters a shared emotional atmosphere among participants (McNeill 1995, 2). The effects of "keeping together in time" also extend to dance, which when seen in such historically varied contexts as celebrations, rituals, and war, often result in temporary but highly intense "boundary loss" between the self and the collective (McNeill 1995, 7-8). Emotional intensity may be brought about through participants intentionally synchronizing their movements, as in drill or formal ritual. Or, it may be brought about unintentionally and nonconsciously in contexts such as mass political rallies and protests (Collins 2004, 73-4). Such large gatherings usually involve some notion of set goals, generally recognized and manageable rules, and allow adjusting the performance level to individual capabilities (Páez and Rimé 2014, 205-6).

Music vividly illustrates the power of rhythm to intensify collective emotions. On an individual register, most people recognize the emotional power of music through toe-tapping, singing, and dancing. Similarly, singing cadence during military drill, workers singing to facilitate sychrony during physical tasks, ritual chanting across religions, and mass singing during concerts all attest to the power of music in collective rhythmic experience. As music is able to bring about similar physical and emotional responses in different people at the same time, it can draw together groups and produce a sense of unity (Storr 1992). This is likely why music has long been associated with the politics of mass mobilization (Damodaran 2016). ${ }^{10}$ McNeill $(1995,2)$ refers to such collective rhythmic intensities as "euphoric fellow feeling," and is observed across a wide array of cultures and contexts (Páez and Rimé 2014). Intensification of emotion matters analytically because it produces pro-social feelings of solidarity and unity, which coalesces group cohesion and efforts during tense times such as protests and uprisings. "Mutual entrainment" in collective contexts fosters feelings of

\footnotetext{
${ }^{10}$ See also Franklin (2005).
} 
“confidence, elation, strength, enthusiasm, and initiative in taking action" (Collins 2004, 49). Emotionally intensive synchronic movements tend to enhance prosocial feelings towards other members of the group, which has the crucial effect of increasing cooperation with others "through strengthening the sense of unity and similarity with others" (Páez and Rimé 2014, 207; Van Baaren et al. 2004). Not only group members, but audiences observing a rhythmic assembly attribute to them greater feelings of mutual understanding (Lakens and Stel 2011), thus amplifying outsiders' impressions of the cohesiveness and power of the assembly.

Second, collective rhythms often generate emergent identities and subjectivities. One of the most widely reported aspects of the Arab Spring were feelings of emergent and novel political subjectivities during the course of the events. Often in mass gatherings identity changes occur and new subjectivities are constructed. While identities constructed around grievances against the state may initially motivate protest behavior (Dalacoura 2012; Pearlman 2013), these identities often transform during the course of events through processes of interaction and interpretation between groups. For example, when crowd members hold a different interpretation of their social standing to those held by an out-group (eg, protestors who see themselves as peaceful, versus police who see them as potential threats), and where the out-group has power to act upon the crowd in terms of its understandings, then crowd members may find themselves in an unexpected set of social relations and can lead to changed self-understandings (Drury and Reicher 2000).

Yet, it is often through the movements of rhythmic intensities themselves that such transformations also occur. One Libyan protestor, for example, vividly described this process: "We started chanting 'It is now your turn, dictator Muammar,' referring to the Arab dictators who were toppled before Qaddafi. With these words, I felt as if all the fetters with which I had been bound were breaking, and I felt the delightful taste of the word "freedom"” 
(al-Khinjari 2015, 129). Similar widespread reports of rhythmic intensities have been an overlooked factor in the generation of subjectivities. Complementing and catalyzing shifting interpretations of changed sets of social relations, the prosocial and "euphoric fellow feelings" that emotionally intensive rhythms foster help to generate new senses of self, even if temporarily. In such contexts, "while there is a historical continuity between the self that intended to act and the (empowered) self that emerges from this self-determined action, they may not necessarily be the same" (Drury et al. 2005, 324).

Analytically, shifting subjectivities and identities are key because they can facilitate renewed emotional investment in the object of collective attention (such as the ouster of a dictator) (Collins 2004). A couple of factors help to produce these conditions. First, such shifts in subjectivity are unlikely to happen in situations where there is low emotional energy and no discernable focus of collective attention. As Collins $(2004,51)$ explains, a mutual focus of attention is crucial if emotional contagion is to build up in crowd settings. When such interactions "fall flat," however, they are usually characterized by a "lack of momentary buzz, no shared entrainment at all or disappointingly little" (Collins 2004, 51). When this happens, there is "little or no feeling of group solidarity; no sense of one's identity as affirmed or changed, [and] no respect for the group's symbols" (Collins 2004, 51). In this sense, high emotional energy contexts are more likely to stimulate shifts in subjectivity than low emotional energy ones. Coordinated rhythmic action and emotional synchrony often foster "fusions" of identity in collective situations, which further heightens a sense of unity (Páez and Rimé 2014, 206). Second, and more broadly, whether rhythms consolidate existing identities or produce novel ones likely depends in part upon the broader events within which they occur. This is because, given their contingency, rhythms are woven into the particular political context within which they arise, be they settled or unsettled times (Krebs 2015). During settled times, collective rhythmic action may tend to consolidate, or at 
least not fundamentally challenge, existing identities. This is because the pace, frequency, and emotional energy of counter-hegemonic rhythms will likely be occurring under multiple layers of social, cultural, and political constraints. Conversely, during unsettled times, collective rhythmic action may accelerate political changes already under way, as tensions and pressures between hegemonic rhythms and counter-rhythms may be more likely to reveal contingencies in dominant subjectivities and produce space for transformations (Dewey 2009, 155). Within these general conditions, though, it likely remains an empirical question to what degree rhythms re-affirm, challenge, or spark novel subjectivities.

Third, collective rhythms can (re)construct social meanings associated with public spaces. While IR has traditionally examined spaces in terms of Westphalian logics of territory, and early critiques argued that such fixed assumptions about territory were no longer tenable under globalization (Agnew 1994), other research examines space as socially constructed and meaningful (Adamson 2016; Brenner and Elden 2009). As Kohn (2003, 3) suggests, "shared places help forge communities by enabling and constraining the way in which people come together." Public spaces are not only material structures, but facilitate shared political events that come to define the meaning of space and its associated and contested emotions and memories (Parkinson 2012).

Building upon yet taking an analytical step forward from this work, rhythm offers an account not only of how space is socially constructed, but more substantially as everyday social action through which spatial contestation itself occurs. Through a variety of embodied social mechanisms, rhythms travel across multiple spaces and scales of social action. This often happens via largely nonconscious embodied means and feedback among participants (Hatfield et al. 2014), as well as more agentive actions such as expressive gestures, movements, dance, singing, and other sounds (Páez and Rimé 2014, 207). Dense bodily spatialities with a mutual focus of attention (as opposed to loose groupings of people without 
a common focus) are important in crowd contexts for rhythmic contagion (Collins 2004, 82). These mechanisms are also influenced by memories of past rhythmic assemblies in the same space, particularly prominent spaces of traditional national attention (Said 2015).

As rhythms travel through these mechanisms they often contest, unsettle, and (re)constitute the spaces through which they move. Rhythms can facilitate spatial meaningmaking through the activities usually considered to characterize the space, such as gendered rhythms of the household, or ritual rhythms associated with national squares and malls (Parkinson 2012). During protests and uprisings, collective rhythms of physical occupation itself both contest and (re)construct space. As Butler $(2015,178)$ observes about the 2011 Arab demonstrations, "temporal seriality and coordination, bodily proximity, auditory range, coordinated vocalization - all of these constitute essential dimensions of assembly and demonstration." While spaces are often stabilized by regular rhythmic patterns (whether official or informal), other rhythms disrupt and challenge existing meanings that may dominate a space, and in doing so can challenge broader power relations.

In sum, rhythms are common phenomena across a wide range of social contexts, and can have significant socio-political effects. As collective, embodied, and affective phenomena, rhythms can bring about the emergence of novel political formations and effects (intensity, generation, (re)construction). In this sense, a rhythmic analytical approach requires a multi-scalar mixed ontology that emphasizes the assembled character of these multiple elements fusing together. Indeed, given the mutually amplifying and reciprocal feedback process amongst these factors, such rhythms are perhaps best viewed through an assemblage lens, "as a decentered, heterogenous alignment of emerging and constantly moving parts" (Bleiker 2014, 79). These themes offer the outline of an initial framework for analysing rhythms' key roles in global politics. To illustrate, the next section turns to the 2011 Arab uprisings. 


\section{Rhythm in the Arab uprisings}

Rhythms were core aspects of experiences of participating in the Arab Spring protests, yet have been neglected in most of the existing literature. Much work on the origins and spread of the uprisings has rightly focused on political and economic grievances (Dalacoura 2012, Gunning and Baron 2013), international pressures (Lawson 2015), social media (Castells 2012), and diffusion and network effects (Patel, Bunce, and Wolchik 2014; Solingen 2012). The significance of these causal factors in sparking the origins of the protests is certainly not disputed here. Yet, after these initial multi-causal sparks were lit, a multitude of rhythms emerged and began to not only carry forward collective momentums but also facilitated a number of significant political effects and transformations which dramatically shaped peoples' experiences and the course of events.

Rhythms help to facilitate the emotional contagion both within crowd contexts in public spaces and across the region via social media that was necessary for bringing about the large-scale changes that occurred. Rhythmic synchronization - often via largely unintended facial, vocal, and postural mimicry and reciprocal feedback - tends to facilitate emotional contagion (Hatfield et al. 2014, 109-13). This is often amplified through social media technologies, which increasingly allow for their widespread diffusion (Castells 2012); in "the age of twenty-four-hour news cycle, streaming video, and social networking, 'contagion without contact' has become ubiquitous" (Ross 2014, 30). On the early 2011 Middle East context specifically, long time observer Marc Lynch $(2012,68-9)$ notes that such technologies indeed helped to bring together various publics across the region into similar rhythmic movements. "On an average Friday in February 2011, virtually every city in the Arab world marched to the same beat, chanting the same slogans, watching each other, feeding off a shared energy within a shared narrative ... The political field within which 
these protests unfolded was astonishinly unified. The momentum of events traveled quickly and easily across borders" (Lynch 2012, 68-9).

As participants recounted in their own words, rhythmic iterative action intensified collective emotions, generated emergent identities and subjectivities, and (re)constructed the symbolic meanings of public spaces - which, in mutually amplifying each other, helped to produce the collective mobilizations that led to watershed political transformations.

\section{Intensities}

Multiple kinds of embodied action intensified collective emotional experience. A frequently recounted aspect of this was the feeling of being in a sheer mass with hundreds or thousands of others. In Tunisia, for instance, a young man expressed this kind of intensity: "Masses of people went to downtown Tunis. What a feeling! There were innumerable people yet one goal: to get rid of the dictator ... This was the best moment in the Tunisian Revolution ... and in one voice they shouted the famous demand: 'Dégage!' (Get out!)” (Cherif 2015, 35). An eyewitness in Egypt recounted how she "could see endless streams of people heading slowly but surely towards Tahrir ... The energy was so overwhelming I cried - so peaceful, hopeful, and powerful” (Wiens 2015, 91-2).

Yet more than mere presence of being together in a group, many expressed the visceral energy which specifically rhythmic actions of marching, chanting, and singing produced, and how it bolstered their commitment to the protests. In Bahrain's Pearl Roundabout in Manama, banners and chants echoed those of Cairo: “'Al-sha'b yurid isqat alnizam' [the people want the fall of the regime], the stresses on the final syllable of each word forming a powerful, even mesmeric rhythm” (Tripp 2013, 112). In Egypt, one person expressed a combination of trepidation but also "security of the self" through marching and chanting within a crowd. "Moving ahead toward the unknown, I joined the masses, where we gathered again and began moving in an organized way. Amid the rhythms of the national 
anthem, we chanted and moved in straight lines, evoking Martin Luther King Jr.'s march on Washington and feeling secure and warm next to one another" (al-Abd 2015, 78). A mother from Aleppo, Syria, encapsulates much about these widely noted effects of moving and voicing together:

"And when those words are said, you and two hundred other people are ready to call out, 'The people want the downfall of the regime!' Your voice gets louder and you feel intense feelings: You shudder and your body rises and everything you imagined just comes out. Tears come down. Tears of joy, because I broke the barrier... and am not afraid, I am a free being . . . Sadness and happiness and fear and courage ... . they're all mixed together in that voice, and it comes out very strong" (Quoted in Pearlman 2017, 89). ${ }^{11}$

Music was often central in facilitating such emotional intensities and their associated political commitments. Although attention to music's importance to mass movements often focuses on the cognitive messages of lyrics, collective motion has "unusual capacities to make people melt into a group in feelings of satisfaction, perhaps because so many parts of the brain and body are involved at once" (Jasper 2011, 294). In Tahrir the "atmosphere was equal parts angry rally and jubilant street party. From every direction came defiant speeches, clever new chants, and infectious bursts of music or drumming" (Khalil 2012, 212). A young Egyptian woman similarly recounted that "you see all these people around you chanting the same thing and it triggers something in your mind ... I am somebody new that was born today" (Mason 2013, 14). The emotional intensities of singing and chanting had a number of other complex effects, such as channeling anger, helping to calm nerves while also keeping up morale, and restraining violence (Gunning and Baron 2013, 208). There was also a clear genre of contemporaneous news that focused on the highly visible role of music during the uprisings (BBC 2011; NPR 2011). As Egyptian musician Zakaria Ibrahim noted, "music can

\footnotetext{
${ }^{11}$ It should be noted that although this analysis of interview material from secondary sources contrasts with that of the original sources, the interpretations are not incompatible. For example, while Pearlman (2017) emphasizes the intimacy of personal testimonies of wartime violence in Syria, the emphasis here on the rhythmic aspects of the protests highlights a particular feature of these testimonies.
} 
encourage people to continue to be in the square and recharge their desire and their mind and their spirit" (CNN 2011).

These emotional intensities are key processes, as they spark confidence for further action, solidify commitment to the cause, as well as come to characterize the event itself. For Collins $(2004,49)$, the "mutual entrainment" that occurs in such contexts amongst those caught up in each others' bodily and intersubjective rhythms often produces feelings of "confidence, elation, strength, enthusiasm, and initiative in taking action." Indeed, bold displays of confidence aided in maintaining group cohesion and durability, and likely mattered greatly in encounters with state security forces. A woman in Alexandria, Egypt, for example, recalled how "at some checkpoints, the policeman in command refused to attack us as we chanted out loud: "Selmeya, selmeya" (peaceful, peaceful). The more I walked, the more I felt courage running through my veins. I felt emboldened as I had never felt before" (Hany 2015, 68).

\section{Generation}

Such rhythmic intensities sparked the generation of emergent identities and subjectivities during the course of the uprisings. These shifting subjectivities, in turn, facilitated renewed emotional investment in the objects of collective attention. Theoretically, there are close links between the rhythmic intensification of emotion and the emergence of new or shifting subjectivities. McNeill (1995, 8-10) approaches this idea when discussing "boundary loss" during military drill and in dance, which he defines as "a blurring of selfawareness and the heightening of fellow-feeling with all who share" in the actions. These actions "create and sustain group cohesion; and the creation and maintanence of social groups" (McNeill 1995, 10). A Syrian man expressed this well: "Others joined in and started chanting, 'Freedom!' I got goosebumps ... it was like I wasn't in control of my own body, 
and my legs were moving themselves ... and I merged into the crowd" (Quoted in Pearlman 2017, 81).

Yet the same rhythmic intensities that sustain group cohesion often bring about significant changes in participants' self-conceptions. The links between emotional intensities and the generation of emergent subjectivities was seen across the uprisings. Coordinated rhythmic action and emotional synchrony help facilitate "fusions" of identity, which heighten peoples' sense of unity (Páez and Rimé 2014, 206). The Guardian promoted this idea early in the uprisings with the headline "Something has changed in the Egyptian psyche," a story which declared that "the masses are feeling emboldened" (Guardian 2011a). Many participants themselves described seemingly profound subjective changes that rhythmic actions helped bring about, such as the kind of self-transformation that one Egyptian articulated. "Although they would still fight us in the coming days, we all knew that something profound had just taken place. There was a raised collective consciousness among us. A realization. An epiphany ... We drew strength, courage, and resolve from one another, from our numbers, and from our conviction" (Ghafar 2015, 59). In such a high emotional energy context, novel shifts in subjectivity are much more likely than in low emotional energy situations that "fall flat" (Collins 2004, 51).

Such accounts encapsulated both political but also more personal senses of becoming. Politically, people recounted the feeling within crowds of lifting off authoritarian constraints:

"In these crowds, I rediscovered myself. Revolution, first and foremost, is a liberating act, and I felt that these people were being liberated from tyranny. The Syrian revolution made me fly with joy. I am liberated. I no longer am just a single number in the population of Syria. Each Syrian has discovered his or her potential" (Alzoubi 2015, 208).

Many people pointed to the power of rhythmic shouting and chanting. An Egyptian professor, waving a flag and screaming among the chants, described "her body quivering ... 
'I found my Egypt, and Mubarak cannot take it away from me"” (New York Times 2011a). A

Syrian woman went further in articulating such intense experience:

"I was in a demonstration...I started to whisper, Freedom. And after that I started to hear myself repeating, Freedom, freedom, freedom. And then I started shouting, Freedom! My voice mingled with other voices. When I heard my voice I started shaking and crying. I felt like I was flying. I thought to myself, "This is the first time I have ever heard my own voice." I thought, "This is the first time I have a soul and I am not afraid of death or being arrested or anything else" (Quoted in Pearlman 2017, $80)$.

A few key points are worth noting here. First, these transformations came about after the initial formations of the protests, rather than acting as clear intentions initiating participation from the beginning, and point to the significance of rhythms in carrying forward affective momentums that facilitated feelings of unity. Second, each of these accounts articulate senses of novel identity change emerging from acting in collective concert with others. As McNeill $(1995,2)$ contends, such "muscular bonding" through "keeping together in time" fosters shared emotional experience amongst participants, which tend to enhance pro-social feelings amongst participants leading to greater cooperation (Van Baaren et al. 2004). These processes can also foster perceptions among audiences - such as embattled elites watching on television, or those watching from the sidelines - of greater feelings of solidarity and shared understanding amongst those participating (Lakens and Stel 2011). Rhythms are defined by their "multiplicity and plurality" (Lefebvre 2013, 87) and stem from “energies opposing each other" (Dewey 2009, 155). When these shared intensities are incited through rhythms that are constantly accelerating and decelerating within bodily collectives that are continually shifting from denser to more dispersed spatialities, the novelty of rhythms can generate these kinds of difference and transformation.

\section{(Re)Construction}

These shifting identities occurred within highly symbolic public spaces whose meanings were contested during the course of the demonstrations. Spaces and places are not 
only material phenomena that structure mass events, but also "massive gatherings of bodies [which] can restructure existing topographies of power and eradicate even the most entrenched symbols and practices of repression and compliance" (Schwedler and King 2014, 160). Space, in this sense, is not a neutral category but "an active player in the production of knowledge about politics and its possibilities" (Schwedler and King 2014, 161). The crucial role of public spaces as symbolic anchors for the Arab uprisings - for both protestors and states - was seen in the Bahrain government's demolition of the Pearl Roundabout monument in Manama during demonstrations there in March 2011, an effort to thwart protests (New York Times 2011b). Indeed, as Gregory observes, the strategic importance of space was "clearly visible in leaflets circulating in Cairo that showed approach routes, crowd formations and tactics to be used in public demonstrations: as one observer remarked, 'you can switch off the Internet but not the streets" (Gregory 2013, 238).

As spaces are meaningfully constituted by social context, the kinds of actions that occurred within them (re)constructed them as particular revolutionary spaces. Tahrir square in Cairo was an exemplar in this regard. Estimates stated that one million people occupied the square at the height of the revolution, "reclaiming public space and showing their defiance with their bodies and with their voices - chief among them the slogans, blazoned also on banners, was the one word "Irhal!" [Go!], repeated endlessly" (Tripp 2013, 97). The sense of both the inherent contestability of the meanings attached to the square, as well as the power in wrestling and (re)constructing its meanings, was clear to many. Even before President Hosni Mubarak stepped down, "Egyptians in the square sensed that they were making a fundamental break with the past" (New York Times 2011a). Demonstrators occupied the square, "defended it against pro-regime thugs, then transformed it into an exhibit of multigenerational and multiclass solidarity with its own memorabilia, banners, music, and skits" (New York Times 2011a) 
The "everyday" nature of the rhythms that developed were key to (re)constructing the meanings and symbolic politics of the uprisings. In Tahrir, singing, daily garbage clean-up, cooking, tent set-up, and other daily rhythmic tasks drew together a wide variety of people. As Bilgic argues, “the 'everydayness' of Tahrir attracted more people to protest while blurring the boundaries between 'us' and 'them,' inclusion and exclusion" (Bilgic 2015, 283). As Tripp further notes, the broad cross-section of Egyptian society that participated in the square was "buoyed up by the knowledge of what they had achieved simply by standing up and occupying public spaces, forcing authorities to take them into account. They took strength from the entertainments, discussions, performances and chants that found their own rhythm and gave the impression that the whole of Egyptian public life was represented in the square" (Tripp 2013, 100). One man in Sana'a, Yemen described such scenes with pride: "[during the] sit-in ... We spent our time reciting slogans, signing some songs celebrating the revolution, and volunteering in the organization committees that were taking care of order and security in Change Square" (al-Omari 2015, 186). In Cairo, one recounted:
"Amid continuous, often creative chanting, young men and women are going around collecting rubbish, one of them telling me 'this is our square, our home, we must keep it clean.' People are forming neat queues - something Egyptians never do - to buy tea at improvised stalls. Everywhere everyone is on their best behaviour; a few days later, women will tell me that sexual harassment, an endemic problem in Cairo, is absent from the square" (Quoted in Rashed 2011, 25).

In Damascus, a Syrian woman expressed similar feelings about the power of the everyday rhythms in public spaces:

"The square was lit and people were playing music, with drums and flute. I don't know who grabbed my hands from the left or right, but we started singing and dancing and jumping. It was a party to overthrow the regime . . It was a moment that I will never forget for the rest of my life: the moment I stood together with strangers, dancing and shouting to overthrow Bashar" (Quoted in Pearlman 2017, 82).

The focus on squares spotlights how these rhythms were both rooted in past protests in the same spaces yet also how rhythms within them facilitated novelty and innovation. When asked how they knew to head to Tahrir, many participants responded that "Tahrir was 
simply understood as where the revolution would take place” (Said 2015, 348). Tahrir's past legacy as a site of protests resonated directly with its emergence as a focal point in 2011. As Said $(2015,354)$ argues, the historical significance of Tahrir as a space of contestation in relation to mobilization took form not only as a known target of protest and a site of national meaning, but also as a source of tactical lessons from past efforts about how to stage an occupation.

The importance of occupying public spaces was both a key aspect of the protestor's strategy but also had social effects that emerged during the course of the occupations. Through both conscious (singing, chanting) and nonconscious (postural and vocal mimicry) action, such rhythms traveled across multiple spaces and scales of social action, and in doing so unsettled and (re)constituted public spaces in the process. In Tahrir, rhythmic action was often combined with other repertoires of contestation, such as fraternizing with army personnel (Ketchley 2017, 57). There is also evidence to suggest that rhythms of specific groups were honed as part of their broader organizational practice of resistance, such as the Muslim Brotherhood (Shahin 2012, 58), and soccer clubs (Dorsey 2012).

Alongside such scenes were violent incursions by state security forces. These encounters displayed rhythmic back-and-forth dynamics which shaped the battles themselves. Collective violence often develops patterns of rhythmic engagement (Collins 2008, 5). Across streets and squares, battles between demonstrators and state security forces illustrated compressions of bodily, collective, and novelty rhythms that into accelerated sites of violence. Police and security personnel "began to stamp the heels of their boots rhythmically on the tarmac, and to let out low, guttural sounds. It was meant to be a scary warning. And it worked" (Trombetta 2012, 142). When the "protesters threw rocks at the riot police, the riot police threw them back" (Ghafar 2015, 58). A Tunisian woman recounted how she was "part of a long row of women pushing backwards and forwards against the police line" (Sebystyen 
2011). In Cairo, a reporter witnessed "a huge charge from demonstrators [which] sent the riot police running, but they ... regrouped and are launching fresh assaults on the front wave of protesters" (Guardian 2011b). Another recounted how when met with state police forces, "we were fearless and did not retreat, standing our ground in the face of the tyrannical police force. We continued to chant our slogans in the few moments in which we caught our breath" (Ahram News 2013). Demonstrators "often quickly dispersed and regrouped" in the commotion (Al Jazeera 2011).

\section{Rhythm, mobilization, power}

Rhythmic action mattered to "ordinary" people acting in extraordinary contexts. Current theories of iterative action, in work on practices, habits, and routines, overlook the significance of such mass repetitive action during unsettled times. Although the political rhythms detailed above are certainly "socially meaningful patterns of action" (Adler and Pouliot 2011, 4), it is less clear how practice theories explain the particular key effects of intensities, generation, and (re)construction outside of highly institutionalized contexts. While habit frameworks also focus on the importance of bodily, patterned social action, they tend to emphasize static and less agential aspects of action (Hopf 2010, 540) and thus are less well-equipped to explain the significance of the above effects, as these collective rhythms were not habitual iterative action in everyday life for most. Similarly, while routines are often defined by their repetition and predictability (Steele 2008, 61), the repetitive collective action seen here bears little empirical resemblance to the routinal upholding of social order.

The 2011 uprisings are a highly illustrative case where the power of rhythms was amply on display, and worked in conjunction with a number of other important factors. Rhythms here were largely "successful" in helping to induce novel political changes. In this sense, the Arab uprisings demonstrate the significant political work that rhythms have the potential to effect. In doing so, this case spotlights the potential advantages in studying 
rhythms in a field that, thus far, largely has neglected them. Yet, rhythms will likely not have the same degree of influence in every case where they may be present. For example, while these cases are distinct contexts of authoritarian regimes, no claims are made here regarding the relationship between rhythmic "success" or "failure" and regime type. Rhythms may have important effects within political action across a range of societies whether democratic or authoritarian (as the interdisciplinary literature above suggests), yet it remains an empirical question of how specific socio-political contexts enable or constrain political rhythms of different kinds.

The empirical analysis here, however, suggests that rhythmic action was a significant factor in collective mobilization processes across the Middle East in 2011. More than merely being together in a collective, participants found that rhythmic actions specifically helped to mobilize them and others on visceral, affective, bodily registers. This points to novel perspectives on the growing interest in the power politics of mobilization in IR (Goddard and Nexon 2016; Krebs 2018; Van Rythoven 2017). Much of this work re-casts "power politics" more broadly than traditional anarchical, state-based models. For Goddard and Nexon (2016, 5), collective mobilization is the common thread tying together various frameworks for the study of power politics, whether mainstream or critical. This is because collective mobilization involves, first, collective action aimed at enhancing one's influence at the expense of others, but also, second, the "relations, transactions, practices, and decisions" of actors that make claims about authority (Goddard and Nexon 2016, 7). Bodily, collective, and novel rhythms can constitute and amplify many of the very "relations and transactions" upon which powers of influence and authority are generated, and help to produce the emotional intensities that concatenate and sustain mass mobilizations (Goddard and Nexon 2016, 5; Tilly 2008, 14). 
Yet collective rhythms themselves appear play a more significant role in the power politics of mobilization than has been recognized. In the broader mobilization literature (McAdam et al. 2001; Tarrow 2011; Tilly 2008), rhythms could be considered aspects of "repertoires," or the "ways that people act together in pursuit of shared interests (Tilly 1995, quoted in Tarrow 2011, 39). Many of the ways in which people in the Arab uprisings moved rhythmically together was, in their own words, significant in catalyzing and circulating the effects of emotional intensity, generation of emergent subjectivities, and spatial (re)constructions. Repertories involve "not only what people do when they are engaged with others but what they know how to do and what others expect them to do" (Tarrow 2011, 39, emphasis in original). In other words, much of mobilization is about social meanings and their potential to inspire action. Clearly, as in the cases above, the contestation around meanings of grievances, collective and national identities, and public spaces all played key roles during the course of the protests.

Yet, even as examining social meanings is necessary, it is likely not sufficient when assessed in light of the significance of rhythmic political effects. There is mobilizing power in contesting meanings of socio-economic grievances (Simmons 2016), as well as attempts at discursive legitimation (Krebs 2018). However, a focus only on the symbolic politics of meaning risks overlooking the accompanying rhythmic, affective, and embodied actions that have the potential to (re)shape self-understandings, and the meanings attached to collectives and public spaces. Embodied action works in a complex relation of continual feedback with interpretations of social meanings; each feeds off of the other in recursive self-amplifications. Indeed, as participants above indicate, it is difficult to assess the significance of meaningful or symbolic politics without the embodied and emotional - and rhythmic - aspects of mass mobilization that accompany them. 
These visceral dynamics are constituted through the working together of emotional and micropolitical registers. For Hutchison and Bleiker (2014, 499), the main challenge of micro and macro approaches to emotion is to theorize the processes through which individual emotions become collective and political. These concerns are mirrored in recent IR micropolitical research, whether focused on individual emotions and protest (Pearlman 2013), the micropolitics of affect, space, and time (Solomon and Steele 2017), or the microfoundations of macro-level behavior (Kertzer 2016). Rhythm ties together many of these concerns through a focus on embodied action that has simultaneous affective, temporal, and spatial effects. ${ }^{12}$ Such rhythms generated in mass contexts are more than the sum of their parts, as the power of collective rhythmic effects are often not produced by any of these factors alone. Rhythm is not the only factor at work here, yet it is often a core energizing force through which pathways emerge between individuals and broader social configurations through "shared expression and resonance" (Hall and Ross 2015, 859). Marching, chanting, singing, moving together with common foci and shared moods - "keeping together in time" (McNeill 1995) - spotlights neglected political dynamics that amalgamate into the kinds of structures and changes upon which IR scholars usually focus.

Ultimately, rhythms offer new insights efforts towards power politics. Contemporary debates on repetitive, iterative action all pay attention to power in different ways, ${ }^{13}$ as do broader IR debates (Barnett and Duvall 2005; Berenskoetter 2007). Yet the power of iterative action during unsettled times in mass contexts takes on qualitatively different expression. Indeed, what we might call collective power is often downplayed in a field that has long considered power in its more coercive and "top-down" variants. In Barnett and Duvall's typology, "productive power" emphasizes how discursive practices socially constitute knowledges and subjects (Barnett and Duvall 2005, 55), and this certainly captures

\footnotetext{
12 For related work on time in IR, see Hom 2018 and McIntosh 2015.

13 See Adler and Pouliot 2011, 30-31; Adler-Nissen and Pouliot 2014; Hopf 2010, 544; Steele 2010.
} 
something of the narratives that circulated during the Arab uprisings. However, there are many other productive aspects of power that are not exhausted by IR's prevailing notion (Bilgic 2015), which rhythmic effects often exceed. Rhythm is a core aspect of collective power, which Hannah Arendt $(1970,44)$ defines as "the human ability not just to act but to act in concert. Power is never the property of an individual; it belongs to a group and remains in existence only so long as the group keeps together." Indeed, even before they narrate their claims, crowds make a political statement with their sheer presence in public space, as peoples' bodies themselves make a claim through their very corporeality and

vulnerability (Butler 2015). Rhythm, with its multi-faceted intensities, force, and symbolism, produces the bonds often needed for the generation and expression of collective power, and to challenge the coercive powers usually emphasized in IR.

\section{Conclusions}

IR has rarely explored rhythms of global politics. In response, this article has outlined an initial framework for the study of rhythms in international politics. Delineating some core features of social rhythms and three kinds of political effects, the article contends that rhythms often do significant political work in collective mobilization during key historical junctures.

More generally, a key aim here has been to initiate a conversation on rhythms of global politics. As such, many questions and potential routes of inquiry have necessarily been left aside. Rhythms have been examined here during a major historical event, yet rhythms are also at the center of the most seemingly mundane political sites. Rhythms are just as central to everyday timetables and national calendars as they likely are to violence and war, which raises a number of questions that future work may address. The relationships between different kinds, speeds, and durations of rhythms and various types of power is 
likely a fruitful route of inquiry, as is the question of why and under what conditions do rhythms "succeed" or "fall flat" in their respective contexts.

Normative questions also abound about the political associations of rhythms.

Although rhythms helped facilitate collective power against repression in Arab Spring (even if the changes took very different directions in different states afterwards), rhythms themselves are likely normatively indeterminate. They may be politically emancipatory here and elsewhere. Indeed, authoritarian states commonly ban rhythmic performances because they are seen as subversive, as when Tunisian rap musician El Général was arrested during the 2010 protests after releasing songs critical of President Ben Ali, and when Iran imprisoned six people in 2014 for uploading to Youtube a video of themselves dancing (BBC 2014; Time 2011). Yet rhythms can also generate collective power around reactionary and repressive politics, as seen in chants of "blood and soil" during the far-right rally in Charlottesville, Virginia in 2017 (Washington Post 2017), and in the rhythmic ceremonies of the Nuremberg Nazi Party rallies during the 1930s. Future research may therefore find this most basic of human actions doing surprisingly significant and unrecognized political work, just beyond the scope of our routine scholarly habits.

\section{References}

Adamson, Fiona. 2016. "Spaces of Global Security: Beyond Methodological Nationalism." Journal of Global Security Studies 1 (1): 19-35.

Adler, Emmanuel and Vincent Pouliot. 2011. "International Practices." International Theory 3 (1): $1-36$.

Adler-Nissen, Rebecca and Vincent Pouliot. 2014. "Power in Practice: Negotiating the International Intervention in Libya." European Journal of International Relations 20 (4): 889-911.

Agnew, John. 1994. "The territorial trap: The geographical assumptions of International Relations theory." Review of International Political Economy 1 (1): 53-80.

Åhäll, Linda. 2018. "Feeling Everyday IR: Embodied, affective, militarizing movement as choreography of war." Cooperation and Conflict 54 (2): 149-156. 
Ahram News. 2013. "Reforming the policy is the solution, not the emergency law," February 2, http://english.ahram.org.eg/NewsPrint/63847.aspx.

al-Abd, Al-Mutazbellah Ahmad Ali. 2015. "The Bullets are Still in My Leg." In Voices from the Arab Spring, edited by Asaad Al-Saleh, 78-83. New York: Columbia University Pres.

Al Jazeera. 2011. "Protestors Across Egypt Defy Curfew," January 28, https://www.aljazeera.com/news/middleeast/2011/01/201112816845606511.html

al-Khinjari, Ehab Ibrahim. 2015. "The Dark Night on the Tripoli Front." In Voices from the Arab Spring, edited by Asaad Al-Saleh, 129-132. New York: Columbia University Pres.

al-Omari, Mohammed. 2015. "The Tent and the Revolution." In Voices from the Arab Spring, edited by Asaad Al-Saleh, 185-189. New York: Columbia University Press.

Alzoubi, Odai. 2015. "The Road from Damascus to al-Qaboun." In Voices from the Arab Spring, edited by Asaad Al-Saleh, 206-211. New York: Columbia University Press.

Aradau, Claudia. 2015. “'Crowded Places are Everywhere We Go’: Crowds, Emergency, Politics." Theory, Culture \& Society 32 (2): 155-175.

Arendt, Hannah. 1970. On Violence. New York: Harcourt Publishers.

Barkawi, Tarak. 2017. Soldiers of Empire: Indian and British Soldiers in World War II. Cambridge: Cambridge University Press.

Barnett, Michael and Raymond Duvall. 2005. "Power in international politics." International Organization 59 (1): 39-75.

BBC. 2011. "Is hip hop driving the Arab Spring?" https://www.bbc.co.uk/news/worldmiddle-east-14146243.

BBC. 2014. "Iran: Happy video dancers sentenced to 91 lashes and jail," September 19. https://www.bbc.co.uk/news/world-middle-east-29272732.

Berenskoetter, Felix and Michael Williams, eds. 2007. Power in World Politics. New York: Routledge.

Bilgic, Ali. 2015. “'Real people in real places:' Conceptualizing power for emancipatory security through Tahrir.” Security Dialogue 46 (3): 272-290.

Bleiker, Roland. 2009. Aesthetics and World Politics. Basingstoke: Palgrave Macmillan.

Bleiker, Roland. 2014. "Visual Assemblages: From Causality to Conditions of Possibility." Michele Acuto and Simon Curtis, eds. Reassembling International Theory: Assemblage Thinking and International Relations. Basingstoke: Palgrave, 75-81.

Borch, Christian. 2012. The Politics of Crowds: An Alternative History of Sociology. Cambridge: Cambridge University Press. 
Brenner, Neil and Stuart Elden. 2009. "Henri Lefebvre on State, Space, Territory." International Political Sociology 3 (4): 353-377.

Bueger, Christian and Frank Gadinger. 2015. "The Play of International Practice." International Studies Quarterly 59 (3): 449-460.

Butler, Judith. 2015. Notes Toward a Performative Theory of Assembly. Cambridge and London: Harvard University Press.

Buzsáki, György. 2006. Rhythms of the Brain. Oxford and New York: Oxford University Press.

Canetti, Elias. 1984 [1960]. Crowds and Power. Trans. Carol Stewart. New York: Farrar, Straus and Giroux.

Case, Federica and Caitlin Hamilton, eds. 2015. Popular Culture and World Politics: Theories, Methods, Pedagogies. E-International Relations Publishing.

Castells, Manuel. 2012. Networks of Outrage and Hope: Social Movements in the Internet Age. Cambridge: Polity Press.

Cherif, Noureddine. 2015. "Revolution From the Outside." In Voices from the Arab Spring, edited by Asaad Al-Saleh, 34-37. New York: Columbia University Press.

CNN. 2011. "Tahrir Square musicians keep revolutionary spirit alive," July 26, http://edition.cnn.com/2011/WORLD/meast/07/26/egypt.revolution.music/.

Collins, Randall. 2004. Interaction Ritual Chains. Princeton and Oxford: Princeton University Press.

Collins, Randall. 2008. Violence: A Micro-sociological Theory. Princeton and Oxford: Princeton University Press.

Cornut, Jeremie. 2015. "To be a diplomat abroad: Diplomatic practice at embassies." Cooperation and Conflict 50 (3): 385-401.

Dalacoura, Katerina. 2012. "The 2011 Uprisings in the Arab Middle East: Political Change and Geopolitical implications.” International Affairs 88 (1): 63-79.

Damodaran, Sumangala. 2016. "Protest and Music. In Oxford Research Encyclopedia of Politics, online, http://politics.oxfordre.com/view/10.1093/acrefore/9780190228637.001.0001/acrefore9780190228637-e-81.

Davis, Matt and M.I. Franklin. 2015. "What does (the study of) World Politics Sound like?" in Case, Federica and Caitlin Hamilton, eds. Popular Culture and World Politics: Theories, Methods, Pedagogies. E-International Relations Publishing, 120-147.

Dewey, John. 2009 [1934]. Art as Experience. New York: Perigree. 
Dorsey, James M. 2012. "Pitched Battles: The Role of Ultra Soccer Fans in the Arab Spring." Mobilization 17 (4): 411-418.

Drury, John, and Steve Reicher. 2000. "Collective action and psychological change: The emergence of new social identities.” British Journal of Social Psychology 39 (4): 579-604.

Drury, John, Christopher Cocking, Joseph Beale, Charlotte Hanson, and Faye Rapley. 2005. "The phenomenology of empowerment in collective action." British Journal of Social Psychology 44 (3): 309-328.

Durkheim, Emile. 1965 [1912]. The Elementary Forms of the Religious Life. New York: Free Press.

Duvall, Raymond D. and Arjun Chowdhury. 2011. "Practices of Theory." In International Practices, edited by Emanuel Adler and Vincent Pouliot, 335-354. Cambridge and New York: Cambridge University Press.

Edensor, Tim. 2010. "Introduction: Thinking about Rhythm and Space." In Geographies of Rhythm, edited by Tim Edensor, 1-20. Abingdon: Routledge.

Elden, Stuart. 2004. Understanding Henri Lefebvre: Theory and the Possible. London and New York: Continuum.

El-Ghobashy, Mona. 2011. "Politics By Other Means." Boston Review. November 1. http://bostonreview.net/mona-el-ghobashy-egypt-revolution-tahrir-square.

Enloe, Cynthia. 2014. Bananas, Beaches, Bases: Making Feminist Sense of International Politics. Revised Ed. Berkeley and Los Angeles: University of California Press.

Epstein, Charlotte. 2013. "Theorizing Agency in Hobbes's Wake: The Rational Actor, the Self, or the Speaking Subject?" International Organization 67 (2): 287-316.

Ghafar, Adel Abdel. 2015. "The Moment the Barrier of Fear Broke Down." In Voices from the Arab Spring, edited by Asaad Al-Saleh, 55-59. New York: Columbia University Press.

Goddard, Stacie E. and Daniel H. Nexon. 2016. "The Dynamics of Global Power Politics: A Framework for Analysis.” Journal of Global Security Studies 1 (1): 4-18.

Gregory, Derek. 2013. "Tahrir: Politics, Publics and Performances of Space.” Middle East Critique 22 (3): 235-246.

Guardian. 2011a. "Egypt Protests: Something Has Changed in the Egyptian Psyche," https://www.theguardian.com/world/2011/jan/28/egypt-protests-frontline-reports-cairo

Guardian. 2011b. "Protests in Egypt and Unrest in the Middle East - As It Happened," January 25, https://www.theguardian.com/global/blog/2011/jan/25/middleeast-tunisia.

Gunning, Jeroen and Ilan Zvi Baron. 2013. Why Occupy a Square? People, Protests and Movements in the Egyptian Revolution. London: Hurst \& Company. 
Hall, Todd H. and Andrew A.G. Ross. 2015. "Affective Politics after 9/11.” International Organization 69 (1): 847-879.

Hany, Sara. 2015. "It is Just ... The Beginning." In Voices from the Arab Spring, edited by Asaad Al-Saleh, 67-70. New York: Columbia University Press.

Hatfield, Elaine, Megan Carpenter, and Richard L. Rapson. 2014. "Emotional contagion as a precursor to collective emotions." In Collective Emotions: Perspectives from Psychology, Philosophy, and Sociology, edited by Christian von Scheve and Mikko Salmela, 108-122. Oxford: Oxford University Press.

Hayes, Jarrod. 2015. "Nuclear Disarmament and Stability in the Logic of Habit." The Nonproliferation Review 22(3-4): 505-515.

Hast, Susanna. 2018. Sounds of War: Aesthetics, Emotions, and Chechnya. E-International Relations Publishing.

Holmes, Marcus. 2013. "The Force of Face-to-Face Diplomacy: Mirror Neurons and the Problem of Intentions.” International Organization 67 (4): 829-861.

Hom, Andrew R. 2018. "Timing is Everything: Toward a Better Understanding of Time and International Politics.” International Studies Quarterly 62 (1): 69-79.

Hopf, Ted. 2010. "The Logic of Habit in International Relations." European Journal of International Relations 16 (4): 539-561.

Hopf, Ted. 2017. “Change in International Practices.” European Journal of International Relations, online early view.

Howard, Lisa Morje. 2015. "US Foreign Policy Habits in Ethnic Conflict." International Studies Quarterly 59 (4): 721-734.

Hutchison Emma and Roland Bleiker. 2014. "Theorizing emotions in world politics." International Theory 6 (3): 491-514.

Fierke, Karin. 2013. Political Self-Sacrifice: Agency, Body and Emotion in International Relations. Cambridge and New York: Cambridge University Press.

Franklin, M.I. 2005. Resounding International Relations: On Music, Culture, and Politics. Basingstoke: Palgrave Macmillan.

Jasper, James M. 2011. "Emotions and Social Movements: Twenty Years of Theory and Research.” Annual Review of Sociology 37: 285-303.

Keohane, Robert O. 1984. After Hegemony: Cooperation and Discord in the World Economy. Princeton: Princeton University Press.

Kertzer, Joshua. 2016. "Microfoundations in International Relations." Conflict Management and Peace Science 34 (1): 81-97. 
Ketchley, Neil. 2017. Egypt in a Time of Revolution: Contentious Politics and the Arab Spring. Cambridge: Cambridge University Press.

Khalil, Ashraf. 2011. Liberation Square: Inside the Egyptian Revolution and the Rebirth of a Nation. St. Martin's Press.

Kinnvall, Catarina. 2004. "Globalization and Religious Nationalism: Self, Identity, and the Search for Ontological Security.” Political Psychology 25 (5): 741-767.

Kinnvall, Catarina and Jennifer Mitzen. 2017. "An Introduction to the Special Issue: Ontological Securities in World Politics." Cooperation and Conflict 52 (1): 3-11.

Knottnerus, J. David. 2014. "Religion, Ritual, and Collective Emotion." In Collective Emotions: Perspectives from Psychology, Philosophy, and Sociology, edited by Christian von Scheve and Mikko Salmela, 312-325. Oxford: Oxford University Press.

Kohn, Margaret. 2003. Radical Space: Building the House of the People. Ithaca: Cornell University Press.

Krebs, Ronald R. 2015. Narrative and the Making of US National Security. Cambridge and New York: Cambridge University Press.

Krebs, Ronald R. 2018. "The Politics of National Security." In The Oxford Handbook of International Security, edited by Alexandra Gheciu and William C. Wohlforth, 250-273. Oxford: Oxford University Press.

Lakens, D., and Stel, M. 2011. "If they move in sync, they must feel in sync: movement synchrony leads to attributed feelings of rapport." Social Cognition 29 (1): 1-14.

Langus, Alan, Jacques Mehler, and Marina Nespor. 2016. "Rhythm in Language Acquisition." Neuroscience \& Biobehavioral Reviews, 81 (B): 158-166.

Lawson, George. 2015. "Revolution, Nonviolence, and the Arab Uprisings." Mobilization: An International Quarterly 20 (4): 453-470.

Lefebvre, Henri. 2013 [1992]. Rhythmanalysis: Space, Time, and Everyday Life. Bloomsbury.

Lynch, Marc. 2012. The Arab Uprisings: The Unfinished Revolutions of the New Middle East. Public Affairs.

Mason, Paul. 2013. Why It's Still Kicking Off Everywhere: The New Global Revolutions. $2^{\text {nd }}$ Edition. London and New York: Verso.

McAdam, Doug, Sidney Tarrow, and Charles Tilly. 2001. Dynamics of Contention. Cambridge: Cambridge University Press.

McCourt, David M. 2016. "Practice Theory and Relationalism as the New Constructivism." International Studies Quarterly 60 (3): 475-485. 
McIntosh, Christopher. 2015. "Theory across time: the privileging of time-less theory in international relations." International Theory 7 (3): 464-500.

McNeill, Wiliam. 1995. Keeping Together in Time: Dance and Drill in Human History. Cambridge: Harvard University Press.

Mercer, Jonathan. 2013. "Emotions and Strategy in the Korean War." International Organization 67 (2): 221-252.

Mills, Dana. 2016. Dance and Politics: Moving Beyond Boundaries. Manchester University Press.

Mitzen, Jennifer. 2006. "Ontological Security in World Politics: State Identity and the Security Dilemma.” European Journal of International Relations 12 (3): 341-370.

Mitzen, Jennifer and Randall L. Schweller. 2011. "Knowing the Unknown Unknowns: Misplaced Certainty and the Onset of War." Security Studies 20 (1): 2-35.

Morgan, Patrick M. 2011. "The practice of deterrence." In International Practices, edited by Emmanuel Adler and Vincent Pouliot, 139-173. Cambridge: Cambridge University Press.

Neumann, Iver. 2002. "Returning Practice to the Linguistic Turn: The Case of Diplomacy." Millennium: Journal of International Studies 31 (3): 627-651.

New York Times. 2011a. “The Legacy of 18 Days in Tahrir Square,” Feb. 19, https://www.nytimes.com/2011/02/20/weekinreview/20tahrir.html.

New York Times. 2011b. "Bahrain Tears Down Monument as Protests Seethe," March 18, https://www.nytimes.com/2011/03/19/world/middleeast/19bahrain.html.

NPR. 2011. "The rap songs of the Arab Spring.” June 9. https://www.npr.org/sections/therecord/2011/06/09/137067390/the-rap-songs-of-the-arabspring? $\mathrm{t}=1539951526418$.

Oren, Ido and Ty Solomon. 2015. "WMD, WMD, WMD: Securitisation through ritualized incantation of ambiguous phrases." Review of International Studies 41 (2): 313-336.

Orr, Graeme. 2015. Ritual and Rhythm in Electoral Systems: A Comparative Account. London and New York: Routledge.

Páez, Dario and Bernard Rimé. 2014. "Collective emotional gatherings: their impact upon identity fusion, shared beliefs, and social integration." In Collective Emotions: Perspectives from Psychology, Philosophy, and Sociology, edited by Christian von Scheve and Mikko Salmela, 204-216. Oxford: Oxford University Press.

Parkinson, John R. 2012. Democracy and Public Space: The Physical Sites of Democratic Performance. Oxford and New York: Oxford University Press. 
Patel, David, Valerie Bunce, and Sharon Wolchik. 2014. "Diffusion and Demonstration." In The Arab Uprisings Explained: New Contentious Politics in the Middle East, edited by Marc Lynch, 57-74. New York: Columbia University Press.

Pearlman, Wendy. 2013. "Emotions and the Microfoundations of the Arab Uprisings." Perspectives on Politics 11 (2): 387-409.

Pearlman, Wendy. 2017. We Crossed a Bridge and It Trembled: Voices From Syria. New York: Custom House.

Pouliot, Vincent. 2010. International Security in Practice: The Politics of NATO-Russia Diplomacy. Cambridge: Cambridge University Press.

Prince, Mona. 2015. "Funny Beginnings and Happy Endings." In Voices from the Arab Spring, edited by Asaad Al-Saleh, 60-63. New York: Columbia University Press.

Pruitt, Lesley. 2013. Youth Peacebuilding: Music, Gender, and Change. Albany: State University of New York Press.

Rashed, Mohammed Abouelleil. 2011. "The Egyptian Revolution.” Anthropology Today 27 (2): $22-27$.

Ross, Andrew A.G. 2014. Mixed Emotions: Beyond Fear \& Hatred in International Conflict. Chicago and London: University of Chicago Press.

Said, Atef. 2015. "We Ought to Be Here: Historicizing Space and Mobilization in Tahrir Square.” International Sociology 30 (4): 348-366.

Schindler, Sebastian and Tobias Wille. 2015. "Change In and Through Practice: Pierre Bourdieu, Vincent Pouliot, and the End of the Cold War." International Theory 7 (2): 330359.

Schwedler, Jillian and Ryan King. 2014. "Political Geography." In The Arab Uprisings Explained, edited by Marc Lynch, 160-179. New York: Columbia University Press.

Sebystyen, Amanda. 2011. "Voice from the Tunisian Revolution." Red Pepper magazine, 23 May: https://www.redpepper.org.uk/voices-from-the-tunisian-revolution/.

Shahin, Emad El-Din. 2012. "The Egyptian Revolution: The Power of Mass Mobilization and the Spirit of Tahrir." The Journal of the Middle East and North Africa 3 (1): 46-69.

Simmons, Erica. 2016. Meaningful Resistance: Market Reforms and the Roots of Social Protest in Latin America. Cambridge: Cambridge University Press.

Smith, Anthony. 1991. National Identity. Reno and Las Vegas: University of Nevada Press.

Solingen, Etel 2012. "Of Dominoes and Firewalls: The Domestic, Regional, and Global Politics of International Diffusion.” International Studies Quarterly 56 (4): 631-644. 
Solomon, Ty and Brent J. Steele. 2017. "Micro-moves in International Relations Theory." European Journal of International Relations 23 (2): 267-291.

Stanley, Liam and Richard Jackson. 2016. "Introduction: Everyday Narratives and World Politics." Politics 36 (3): 223-235.

Steele, Brent J. 2008. Ontological Security in International Relations: Self-Identity and the IR State. London and New York: Routledge.

Steele, Brent J. 2010. Defacing Power: The Aesthetics of Insecurity in Global Politics. Ann Arbor: University of Michigan Press.

Storr, Anthony. 1992. Music and the Mind. New York: Ballantine Books.

Swidler, Ann. 1986. "Culture in Action: Symbols and Strategies. "American Sociological Review 51(2), 273-286.

Sylvester, Christine. 2013. "Experiencing the Ends and Afterlives of International Relations Theory." European Journal of International Relations 19 (3): 609-626.

Tarrow, Sidney G. 2011. Power in Movement: Social Movements and Contentious Politics. Revised and Updated Third Edition. Cambridge: Cambridge University Press.

Tilly, Charles. 2008. Contentious Performances. Cambridge: Cambridge University Press.

Time. 2011. "El General and the Rap Anthem of the Mideast Revolution. http://content.time.com/time/world/article/0,8599,2049456,00.html. February 15.

Tripp, Charles. 2013. The Power and the People: Paths of Resistance in the Middle East. Cambridge: Cambridge University Press.

Trombetta, Lorenzo. 2012. "More than just a background: Cairo's urban space during the 2011 protests." European Urban and Regional Studies 20 (1): 139-144.

Uhlhaas, Peter J. and Wolf Singer. 2006. "Neural Synchrony in Brain Disorders: Relevance for Cognitive Dysfunctions and Pathophysiology." Neuron 52 (1): 155-168.

Valdesolo, Piercarlo, Jennifer Ouyang, and David DeSteno. 2010. "The Rhythm of Joint Action: Synchrony Promotes Cooperative Ability.” Journal of Experimental Social Psychology 46 (10): 693-695.

Van Ness, Justin and Erika Summers-Effler. 2016. "Reimagining Collective Behavior." In Handbook of Contemporary Sociological Theory, edited by Seth Brutyn, 527-546. Springer.

Van Baaren, Rick., Holland, Rob.W., Kawakami, Kerry., and van Knippenberg, Ad. 2004. "Mimicry and prosocial behavior." Psychological Science 15 (1): 71-74.

Van Rythoven, Eric. 2017. "Fear in the Crowd or Fear of the Crowd? The Dystopian Politics of Fear in International Relations." Critical Studies on Security 6 (1): 33-49. 
Waltz, Kenneth N. 1979. Theory of International Politics. Addison-Wesley.

Washington Post. 2017. "Deconstructing the Symbols and Slogans Spotted in Charlottesville." August 18, https://www.washingtonpost.com/graphics/2017/local/charlottesvillevideos/?utm term=.e9d3bcd9b352.

Weil, Zachary M. and Randy J. Nelson. 2014. "Introduction to the Special Issue on Circadian Rhythms in Behavioral Neuroscience." Behavioral Neuroscience 128 (3): 237-239.

Wendt, Alexander. 1999. Social Theory of International Politics. Cambridge: Cambridge University Press.

Wiens, Claudia. 2015. "Diary to Democracy (Inshallah [God Willing])." In Voices from the Arab Spring, edited by Asaad Al-Saleh, 88-93. New York: Columbia University Press.

Wilcox, Lauren B. 2015. Bodies of Violence: Theorizing Embodied Subjects in International Relations. Oxford and New York: Oxford University Press.

Wiltermuth, Scott S and Chip Heath. 2009. "Synchrony and Cooperation." Psychological Science 20 (1): 1-5.

You, Haili. 1994. "Defining Rhythm: Aspects of an Anthropology of Rhythm." Culture, Medicine, \& Psychiatry 18 (3): 361-384.

Zarakol, Ayse. 2010. “Ontological (In)Security and State Denial of Historical Crimes: Turkey and Japan.” International Relations 24 (1): 3-23.

Zimmer, Oliver. 2013. Remaking the Rhythms of Life: German Communities in the Age of the Nation-State. Oxford and New York: Oxford University Press. 